\title{
Breakdowns and Breakthroughs: Observing Musicians' Responses to the COVID-19 Pandemic
}

\author{
Carrie J. Cai \\ cjcai@google.com \\ Google Research \\ Mountain View, CA, USA \\ Nida Zada \\ nzada@google.com \\ Google Research \\ Mountain View, CA, USA
}

\author{
Michelle Carney \\ michellecarney@google.com \\ Google Research \\ Mountain View, CA, USA \\ Michael Terry \\ michaelterry@google.com \\ Google Research \\ Cambridge, MA, USA
}

\begin{abstract}
This paper describes results from a study examining how musicians have been affected by the restrictive environments imposed by the COVID-19 pandemic, and the corresponding technological implications. Through a survey of 29 musicians and additional interviews with 7 professional improvisation musicians, we observe the challenges musicians face in 1) finding the technological infrastructure and shared spaces necessary for dynamic, remote creative collaborations, 2) producing the mindset, free time, and sources of inspiration necessary for initiating creativity during times of stress, and 3) maintaining (and potentially expanding) the social connections and creative community vital to creative practice. We also report on how some musicians have creatively leveraged the radical changes in their lives to drive new artistic practices and styles of music. Collectively, these data illustrate the resilience of certain existing remote collaboration and creative tools, while suggesting ways other digital tools could more flexibly accommodate new use cases. The data also suggest the value of tools and services that help people creatively cope with radical changes to their lives and livelihoods.
\end{abstract}

\section{CCS CONCEPTS}

- Human-centered computing $\rightarrow$ Empirical studies in HCI.

\section{KEYWORDS}

remote collaboration, life disruption, COVID-19, creativity support tools

\section{ACM Reference Format:}

Carrie J. Cai, Michelle Carney, Nida Zada, and Michael Terry. 2021. Breakdowns and Breakthroughs: Observing Musicians' Responses to the COVID19 Pandemic. In CHI Conference on Human Factors in Computing Systems (CHI '21), May 8-13, 2021, Yokohama, Japan. ACM, New York, NY, USA, 13 pages. https://doi.org/10.1145/3411764.3445192

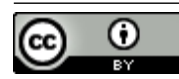

This work is licensed under a Creative Commons Attribution International 4.0 License.

CHI '21, May 8-13, 2021, Yokohama, Japan

(c) 2021 Copyright held by the owner/author(s).

ACM ISBN 978-1-4503-8096-6/21/05.

https://doi.org/10.1145/3411764.3445192

\section{INTRODUCTION}

This paper examines how the creative practices of music-makers have been affected and transformed by the COVID-19 pandemic. We define "music-makers" broadly as individuals who improvise, compose, arrange, and/or perform music. Our results derive from a survey of 29 music-makers and in-depth interviews with 7 improv musicians across the United States between April and June 2020. These participants included hobbyists and professionals; improvisers, composers, and performers; and solo music-makers and collaborative music-makers. By sharing the stories of these individuals, we gain insight into the flexibility and limitations of existing computational tools and services when creatives are faced with extreme disruptions to their practices, livelihoods, and personal lives.

The challenges reported by participants after the onset of the pandemic highlight the importance that physical space, time, proper mindsets, and social connection all have on creative music-making practices. We use these themes of space, time, mindset, and social connections to organize and convey our findings: Within each theme, we identify specific challenges participants faced, how they responded creatively to the challenges, and the opportunities for technology to help mitigate these challenges. The paper's specific contributions, viewed across these themes, are as follows:

- Space: Restrictions on the use of space have highlighted the many nuanced ways musicians leverage physical space, different types of space, and changes in physical location, to support their creative practice. Specifically, participants described how space is used as a creative trigger to encourage one to start making music; as a creative input and creative prompt (e.g., drawing inspiration from viewing the variety in physical environments when walking around); as a means to create psychological safe spaces to support creative risk taking; and as a tool for coordinating live collaborations (by adding or removing people to live improv sessions). These rich uses of space have been difficult to replicate in the pandemic with current digital tools.

- Time: For some, the pandemic has led to less time to engage in music-making, and for others, more time. In both cases, participants described challenges in maintaining the desired level of creative practice in light of the changes to their daily schedules. For those who now experience highly 
fragmented schedules with little time for music-making, there appear to be opportunities for technology that supports micro-creativity in the interstitial moments of their days. For those with a greater abundance of time, there are opportunities for helping musicians structure their time and for encouraging more long-term intentionality in their creative practice.

- Creative mindset and stress: Pandemic-induced stress has led to a profound loss of energy and motivation to engage in creative practice. Though a few have attempted to cope by actively creating music for their own relaxation and stress relief, others desired external, persuasive triggers to reengage them in music-making.

- Social connection: For many musicians, creative practice occurs within social contexts: they perform for, play with, and/or compose with others. Cast into a world of remote communication, musicians must now actively work to maintain the social facets of music-making vital to their work. In many cases, internet latency is an enormous issue due to the realtime requirements of live music and the synchronous, joint composition of new music. Musicians have responded by developing asynchronous collaborative practices; embracing the latency to produce new styles of music; and by building new virtual communities. Some of the adaptations developed reveal limitations in current digital tools (e.g., the difficulty in extending existing desktop applications into synchronous remote collaboration contexts), while others highlight advantages that remote communication tools can afford (e.g., in some cases, the new communities that have formed have provided the community with new, more direct, and/or increased access to experts in the field).

The challenges musicians faced in maintaining desired creative practices, and the adaptations and workarounds they developed, suggest a number of design implications. Specifically, there appears to be value in 1) improving the ability to remotely and synchronously collaborate when using content creation tools (e.g., providing the ability to transform arbitrary digital creative tools into forms that enable real-time collaboration with multiple users, as shown by Sun et al. [54]), 2) tools that help people cultivate the mindset, free time, and sources of inspiration necessary for initiating and maintaining creative pursuits during times of stress, and 3) systems that aid the maintenance (and potential expansion) of the social connections and community vital to creative practice.

Notably, in some cases, relevant research and commercial products that could help musicians with these challenges do exist. For example, online jamming platforms (e.g. Ohmstudio, Jamkazam, Endlesss), streaming services, and Sun et al's aforementioned work [54] could each help musicians better achieve desired goals. However, we found that musicians were often unaware of this relevant research or technology, or, in some cases, felt the software either involved considerable setup or were not compatible with software they were already accustomed to using. Some did not feel they had yet acquired the necessary skills or knowledge to effectively use it.

The rest of the paper contextualizes this work, unpacks these themes, and discusses implications of the findings.

\section{RELATED WORK}

The experiences of the musicians in our study can be considered through the contexts of life disruptions; distanced creative work and computer-supported collaborative work; and creativity and stress.

\subsection{Life Disruptions}

A rich literature exists describing the roles of information and communication technologies (ICTs) within crises, and during changes and disruptions to life. Changes and disruptions to daily life can be minor or significant, with some observing that change is a "fundamental dimension of existence" [46]. When faced with significant changes or disruptions to one's life (e.g., a death in the family), these disruptions "ripple" through people's lives and routines, with individuals needing to work toward a "new normal" [39]. This new normal is characterized by a "reconfigured lifestyle where previous social and technical infrastructures have been torn down and replaced with tenuous and emerging social groups and resources" [39]. Our study of music-makers in the early stages of the pandemic resonates with these descriptions: music-makers experienced disruptions throughout their daily lives and creative routines, and were actively constructing new routines and practices to cope with the new normal.

Life disruptions can also fundamentally affect how and what technology is used [18]. Prior research notes how previously "invisible" infrastructure often becomes visible upon life disruptions and breakdowns $[50,52]$. As a result, people cope by engaging in "routine infrastructuring" by using, re-purposing, or building new infrastructure to restore control over their own lives, including generating new ways of experiencing their social worlds [50].

As has been observed in other disruptive events [39, 50], our participants' existing digital infrastructure failed to completely support them through the changes brought on by the pandemic. For example, existing desktop applications (e.g., music recording software) could not be transformed into remotely accessible music-making tools, leading to participants re-appropriating communications infrastructure to maintain creative practice (e.g., using email to share music files).

While disruptions are rarely welcomed, rebuilding and transforming infrastructure to meet new realities can also be a driver of innovation [23]. In our study, we saw evidence of this occurring when musicians leveraged the latency of remote communication tools to develop new styles of music, or when they found new sounds for music in their home, both a result of a change to their overall work environment (i.e., their homes).

Mekler and Hornbæk's framework for meaning posits that when meaning is disrupted or threatened by stressful events, people are motivated to reinstate a sense of meaning through the dimensions of connectedness, purpose, coherence, resonance, and significance [40]. In our study, participants' desire to sustain their creative practices often went beyond the basic desire to make a living or continue a hobby; as suggested by Mekler and Hornbæk's work, our participants also sought to preserve a sense of meaning and purpose in their lives.

In sum, the experiences of the music-makers in our study share similarities to those described in prior work examining people's 
lives in the face of disruption. This study's results complement this body of literature by documenting how a community of creative practice has coped with a relatively sudden, nearly universal disruption to their routine practices.

\subsection{Remote Work and Creativity}

In their foundational study examining the differences between collocated and remote work, Olson and Olson [44] observe that collocation affords communication via multiple channels with rapid feedback, nuanced communications, and a common local context to help ground work. These features of collocated work can be difficult to replicate remotely. In our study, the many virtues and affordances of collocated music-making practices were made apparent in participants' descriptions of what was difficult to recreate through remote collaboration tools (e.g., psychologically safe spaces for creative risk taking were cited as being relatively easy to create when physically collocated, but challenging to do in an online setting).

In the realm of creative work, prior research has investigated the specific challenges and opportunities unique to conducting creative work remotely. For example, some found that novel ideas, minority ideas, and critical evaluations of ideas are more easily lost in distributed work [20], and that obtaining group resonance can be challenging without greater support for socio-emotional or affective communication [3]. Others uncovered the cognitive strategies that artists employ to navigate dispersed collaborations [42], and suggest it may be beneficial to support multiple group configurations as well as flexible and opportunistic (rather than purely structured) coordination during distributed creative tasks [19]. Independent of geographical location, fundamental theories of distributed cognition [30] and distributed creativity [48] posit that there are essential elements of group creativity that exist outside of any particular individual, arising through the relationships constructed by individuals between themselves and their environments and tools. In our study, we saw these types of relationships severely disrupted with the shift to remote collaborations.

Within the music domain, research has investigated design requirements for facilitating collaboration during group music creation [10,35], such as localization (the ability to indicate which aspect of the artifact one is referring to), mutual awareness, mutual modifiability, and a shared and consistent representation. Researchers have also explored design interventions for facilitating social coordination during ensemble improvisation, such as signaling group configurations to other players [17], sound visualizations to show who did what [41], or encouraging more spontaneity through novel representations of music [8]. To support distributed music-making, network music systems have been designed for both real-time and non-real-time collaborative music creation, ranging from LAN systems for local collaboration (JAMSpace [24]), to the World Wide Web for remote music-making (e.g. SoundWIRE [15], FMOL [32]). However, most require somewhat complex setups that everyday musicians often do not have access to or experience in setting up. In most remote music-making settings, latency has been a key challenge to real-time collaboration, as was also seen with our participants. In general, our results suggest the utility and applicability of these various research efforts, while highlighting the relatively limited uptake of these innovations in the practices and tools of our participants.

\subsection{Creativity and Stress}

Prior work has found that stress can both increase and decrease creativity. For instance, stressors can decrease creativity by diverting mental resources to attend to stressors, leaving fewer cognitive resources available for producing original ideas $[6,57]$. However, there is also evidence that stressors may increase creativity through increasing arousal [1], inducing more focused problem-solving [9], and providing cognitive stimuli [2]. Byron et al. found a complex relationship between stress and creativity: while a low level of stress can increase creativity, high levels of stress decrease creativity [12]. In our study, we found that while a substantial number of participants had difficulties getting into a creative mindset due to pandemic-induced stress, several innovated new creative experiences in light of pandemic constraints.

It has also been found that creative acts themselves can help lower stress levels $[38,43]$. A large body of work investigates how to use music and creative therapy as techniques to reduce stress $[25,34,58,60]$ and induce emotional responses [53] with different populations. Creative Art Therapies (e.g. the creation of music, art, dance, and drama) show promise for stress prevention and therapy through their enactment of creation and generativity, nonverbal communication, as well as hedonism and play [38]. Similarly, gaming can also be used as a mechanism to cope with difficult life experiences [31]. In our study, some of the participants turned to music-making as a way to cope with pandemic stressors, creating new songs for friends and loved ones. However, most found it difficult to initiate creativity while stressed, despite acknowledging that music-making could help them cope with stress itself.

In the wake of COVID-19, the circumstances created by the global pandemic have provided new urgency and relevance to the research themes laid out above. Building on this body of prior work, this work describes how music-makers responded to and actively adapted tools-at-hand to maintain their livelihood and practice, offering insights and implications to guide the design of tools that enable greater resiliency and flexibility in the face of disruption.

\section{METHOD}

To understand how the pandemic has affected musicians' lives and creative practices, we conducted a survey of 29 music-makers in April 2020. Survey participants completed four open-ended questions, describing: 1) the main challenges they have faced making music during the pandemic, 2) music-making strategies they have found useful in response to pandemic-related changes, 3) new music experiences that they have discovered as a result of the pandemic (if any), and 4) technologies that they feel could help them with their music-making during the pandemic.

Social practices brought up in the survey motivated us to conduct seven in-depth interviews with professional music improvisation artists, to gain further insight and depth into music-makers' experiences and practices during the pandemic.

All data from surveys and interviews were transcribed for qualitative data analysis. To analyze the data, two researchers employed open coding to code responses [16]. The researchers then revised 
and examined relationships between codes, identified overarching themes, and iteratively refined these themes through a reflexive process of collaborative discussion and consultation with the codes and data [7].

\subsection{Participants}

Survey participants and interview participants were two distinct groups, with no overlap in participants. We describe the two different groups and methods of recruitment in the subsections below.

3.1.1 Survey Participants. 30 survey participant were recruited across the United States through an online qualitative research platform. One participant dropped out of the study due to noncompletion. The 29 survey participants who completed the study lived in 17 different U.S. states, with ages ranging from 18-74 (median=34). Participants identified as 15 men, 12 women, and 2 nonbinary. Eight (28\%) indicated that music is their full-time job, six indicated it is their part-time job (21\%), and the rest (52\%) were music-making hobbyists/enthusiasts. Among those who do not play music for a living, their main jobs included occupations in apparel, service, education, healthcare, transportation, and telecommunications. Household income ranged from less than $\$ 25 \mathrm{~K}$ to over $\$ 150 \mathrm{~K}$, with seven $(24 \%)$ households earning less than $\$ 50 \mathrm{~K}, 13(45 \%)$ between $\$ 50-100 \mathrm{~K}$, six (21\%) between $\$ 100-150 \mathrm{~K}$, and one above $\$ 150 \mathrm{~K}$ (with the rest not reporting this information). Participants also came from a range of household makeups, including living with a partner/spouse (34\%), partner/spouse and children (28\%), roommates $(14 \%)$, alone $(14 \%)$, and parents (1) (with the rest not reporting).

Survey participants reported playing music (prior to the pandemic) multiple times a day (38\%), once a day (24\%), a few times a week (34\%), and once a week (1). Thirteen (45\%) had $20+$ years of music-making experience, eight (28\%) had 10-20 years of experience, and seven $(24 \%)$ had less than 10 years of experience. A majority played music both alone and in groups (72\%), with the rest playing music solely alone (18\%). Among those with group experience, most had played as part of a duo or in small groups, with much fewer (17\%) having large-group experience as well (e.g. orchestras). In terms of music played, there was a wide variety of genres represented, with the majority of the participants indicating they play at least one of the following categories: pop, rock, jazz, blues, electronic, and classical. Other categories participants played were American folk, avant garde, punk rock, South Asian, and African. The median number of selected genres played was eight.

3.1.2 Interview Participants. Interview participants were recruited through word-of-mouth snowball sampling (and, as mentioned above, were distinct from survey participants). Interview participants had between 16-40 years of professional music improvisation experience, ranging from jazz, funk, and blues, to experimental, contemporary, and new age music. Their instruments of specialty ranged from piano, keyboard, oboe, clarinet, and guitar, to percussion, drums, bass, and vocals, with most having experience on multiple instruments. Most also taught music improvisation in private lesson and/or school settings.

\section{STUDY RESULTS}

The survey results and interviews jointly paint a picture of how the pandemic has disrupted the daily routines, livelihoods, and creative practices of music-makers. As indicated in the Introduction, the results suggest the value in 1) infrastructure and creative spaces that support dynamic, remote, synchronous creative collaborations, 2) inducing the "right" mindset, creating free time, and finding sources of inspiration to support creative practices and 3) maintaining social connections and membership in a larger community of creative practice.

In the subsections that follow, we describe the ways in which the pandemic has disrupted participants' routine use of space, time, creative mindsets, and social connections in their creative practices. Table 1 shows a summary of results. In each of the four areas, we observe how participants have sought a return to equilibrium in their creative practices by repairing what has been affected. In some cases, we find participants have gone beyond repairing practices to actually leverage the disruption as a creative constraint to develop new musical experiences. Finally, in each area, we indicate potential implications for design that can be drawn from how participants have adapted, or failed to adapt, to the specific challenges they have faced. In conveying results, survey participants are denoted P1-P29, and interview participants are denoted P30-P36.

\subsection{Space}

Restrictions in movement and congregating have revealed the numerous ways that space factors into music-makers' creative practices. As with many other people and professions, musicians have experienced disruptions to their creative practices as work has relocated to home contexts. For musicians, family and neighbors working from home equates to fewer soundproof spaces for making music without disturbing others.

Beyond these challenges of re-appropriating home spaces for work, the study results also reveal how space is more than just a physical location in which music is made. Specifically, we found musicians use space as a creative trigger; as a creative input and prompt; to create psychological safe spaces to grow themselves and their music; and as a tool for coordinating people and music-making. These varied uses of space bring to mind the concepts of distributed cognition [28], as well as the distinction that can be made between a physical space and the characteristics of the actual "place" in which work occurs [26].

We found that music-makers mentally associate certain physical spaces with creativity, causing these spaces to serve as creative triggers. For example, interstitial spaces are often triggers for creative experimentation: "Going from the apartment to the elevator...has been those times that I doodle around with vocal sounds." (P18) With family and neighbors home all day, this encroachment of space has led to an inability to organically express oneself in those creative spaces, or in interstitial moments when inspiration hits: "I' $m$ also singing less in the shower... heard a neighbor scream to shut up." (P18)

Participants also described the use of space as a creative input or prompt. For many, being out and about typically provides both the inspiration and direct source for new ideas: "I get a lot of inspiration from my experiences outside and even record sounds from outside to use in my songs." (P8) With limited mobility, a lack of spatial variety 
Table 1: Summary of Results: Musicians' experiences adapting to the COVID-19 pandemic, organized by the themes of Space, Time, Stress, and Social Spheres.

\begin{tabular}{|c|c|c|c|}
\hline & Challenges & Adaptations & $\begin{array}{l}\text { Technological desires / opportuni- } \\
\text { ties }\end{array}$ \\
\hline Space & $\begin{array}{l}\text { - Inability to act on creative trigger } \\
\text { (due to disrupting others) } \\
\text { - Lack of creative input (lack of } \\
\text { spatial variety) } \\
\text { - Lack of psychological safe spaces } \\
\text { - Inability to use space to co- } \\
\text { ordinate people during music- } \\
\text { making }\end{array}$ & $\begin{array}{l}\text { - Using spatial constraint as a } \\
\text { source of creativity (e.g., making } \\
\text { use of sounds in local environ- } \\
\text { ment) } \\
\text { - Incorporating cohabitants into } \\
\text { creative process } \\
\text { - Discovering psychological safety } \\
\text { in private iteration }\end{array}$ & $\begin{array}{l}\text { - Creating spatial variety where } \\
\text { there is none (e.g. virtual reality) } \\
\text { - Support for remote, psychologi- } \\
\text { cal safe spaces } \\
\text { - Support for use of spatial con- } \\
\text { straint as creative input }\end{array}$ \\
\hline Time & $\begin{array}{l}\text { Less time: no time to make music } \\
\text { due to hyper-fragmented time } \\
\text { - More time: lack of creative pur- } \\
\text { pose/productivity due to amor- } \\
\text { phous, unstructured time }\end{array}$ & $\begin{array}{l}\text { - Scheduling time for creativity } \\
\text { - Using newfound time to re- } \\
\text { engage/reflect on past projects } \\
\text { - Finding long-term artistic inten- } \\
\text { tionality }\end{array}$ & $\begin{array}{l}\text { - Behavioral triggers for micro- } \\
\text { creativity } \\
\text { - Support for long-term artistic in- } \\
\text { tentionality and reflection }\end{array}$ \\
\hline Stress & $\begin{array}{l}\text { Lack of: } \\
\text { - Income } \\
\text { - Motivation } \\
\text { - Energy } \\
\text { - Creative mood }\end{array}$ & $\begin{array}{l}\text { - Making/playing music for self- } \\
\text { therapy }\end{array}$ & $\begin{array}{l}\text { - Persuasive, lighthearted triggers } \\
\text { for healthy/creative mindsets } \\
\text { during stress } \\
\text { - Support for creating meditative } \\
\text { and therapeutic music } \\
\text { - Support for creative resilience } \\
\text { during crisis }\end{array}$ \\
\hline Social & $\begin{array}{l}\text { - Inability to creatively respond to } \\
\text { each other in real-time (due to } \\
\text { internet latency, audio degrada- } \\
\text { tion) } \\
\text { - Long iteration cycles in remote } \\
\text { collaborations; deliberate, heavy- } \\
\text { weight communications to coor- } \\
\text { dinate collaboration } \\
\text { - Inability to create visceral feel of } \\
\text { playing in the same room } \\
\text { - Need to move livelihoods and au- } \\
\text { dience online to maintain an in- } \\
\text { come }\end{array}$ & $\begin{array}{l}\text { - Asynchronous composition } \\
\text { - New music styles and social coor- } \\
\text { dination methods (e.g., increased } \\
\text { use of silence in musical styles) } \\
\text { - Large-scale, distributed virtual } \\
\text { ensembles; pro bono forums } \\
\text { - Creating music as a gift to others } \\
\text { - Live-streaming; learning digital } \\
\text { skill sets }\end{array}$ & $\begin{array}{l}\text { - Zero-lag video conferencing plat- } \\
\text { forms } \\
\text { - Ability to use existing creativity } \\
\text { software with multiple, remote } \\
\text { collaborators } \\
\text { - Extend remote communication } \\
\text { tools (e.g., video conferencing) } \\
\text { for domain-specific creative use } \\
\text { cases } \\
\text { - Support for remote awareness } \\
\text { and creative spontaneity } \\
\text { - Support for learning how to } \\
\text { bring their livelihoods online and } \\
\text { how to retain their audience in } \\
\text { an online format }\end{array}$ \\
\hline
\end{tabular}

and changes of scenery have affected the healthy generation of ideas. Instead, the monotony of staying at home has contributed to a lack of creative inspiration and physical energy: "I do lose inspiration just being in the same environment over and over and...you start to feel very sluggish." (P8)

The inability to physically congregate has also made it difficult to establish psychological safe spaces for social creativity, where people feel comfortable taking risks. Safe creative spaces are especially critical in improvisation, where music expression is deeply organic and personal, and where creative feedback often happens viscerally through body language: "You really have to be there as a group. It has to feel like a safe environment." (P31) For professionals, it is that very intimate experience of improvising in the same room that allows strangers to become new friends, growing their community: 
"One thing I love about being a freelancer is I get to play with new people all the time. Sometimes you play with someone you've never met before, and you meet through playing music. If it's all improvised it can be a very intimate thing...I get really inspired by somebody." (P36)

Safe creative spaces are particularly useful for learning without self-judgment and for receiving constructive feedback. Novices new to improvisation may be particularly prone to self-criticism or overintellectualization: "The number one barrier to people improvising is often self-consciousness, self-criticism, and judgment, fear of making a wrong note or embarrassing themselves, and difficulty of achieving an attitude of playfulness." (P31) Giving and receiving constructive criticism is also more difficult to do without the psychological safe space of being collocated. In improvisation communities, psychological safety is so important that educators typically engage novices in explicit exercises to disarm the inner critic, such as "just play your name on the drums...something that is so 100 percent who they are, that there's no way they're gonna think they can't do it." (P32)

Our participants' responses suggest that the shift to other mediums (e.g. online communication channels, asynchronous recording) led to the loss of certain characteristics of safe creative spaces, such as the highly ephemeral nature of playing without any music being recorded, or the ease in creating a shared, intimate local context.

Space can also be used by musicians as a tool and organizational mechanism during music-making. For example, in some communities, dynamically varying the group size during improvisation is one way of encouraging musical contrast within a single piece: "Group size is one of the contrasting elements. From quiet to middling to high energy and back to quiet." (P31) A shift to remote work has made it difficult to leverage this dynamic, real-time manipulation of group size.

4.1.1 Addressing Disruptions to Space. Musicians developed a number of approaches to deal with changes in how they could use space for inspiration, to create psychological safety, or as a tool in musicmaking.

In using space as a creative input, the requirement to work from home has led some to discover variety indoors and stillness outdoors. For example, one participant found new soundbites indoors: "Yesterday, I actually went all around my house trying to find a great sound because I realized I had never done that since I usually just get the sounds from when I'm out." (P8) Others found inspiration in the outdoor stillness: "There have been a few times where I felt extremely creative in the moment...just the stillness of outdoors without all the people out and about as normal." (P29) To inject variety into their days, a participant tried to create contrast in spaces within their reach, such as their own backyard: "I started working on music in my backyard, which is something I had never done, but I just felt like I needed a change of scenery and I enjoyed it." (P8)

Day-long proximity to cohabitants has also introduced new people into one's creativity process. For example, one person found that his activities with his son influenced his own creative process: "Introducing my son to drawing and painting while listening to music. I found that's been inspirational to me because it allows me to see music in a different way, which then helps with the composition process." (P15) Some have involved family members in their musicmaking: "I also started asking my mom to pitch in and listen to my music which is also something I rarely do...It's helping me understand her better and visa versa." (P8) Though these practices in no way restore the experience of meeting new friends through collocated jam sessions, they do introduce new types of creativity with people who would otherwise not be involved with one's music-making. Though one's closest family and roommates may not have the music backgrounds typically embodied by their regular colleagues, there may be precious value in ideating and receiving feedback from trusted individuals-even those without music training.

While musicians seemed to find it challenging to establish the same psychologically safe spaces experienced when collocated, a few discovered other kinds of psychological safety in other aspects of their practices by virtue of being disconnected in space. For example, one professional improviser had shifted from doing real-time, collocated improvisation to remote, asynchronous improvisation where each musician records multiple "takes" on their own and uploads their favorite take, adding a new track to a growing song. This person was surprised to discover the newfound safe space to experiment freely, without having to consider one's immediate effect on others: "I appreciate the permission to bumble around a long time in private. Compared to improvising with people, I find it freeing to know that I can edit afterwards. If I were improvising live, I would consciously be trying to stop playing so that I wouldn't be taking too much space." (P30)

Another musician previously recorded improvisation in professional studios, in the presence of business partners who had hired him (e.g., a songwriter or producer). With the shift to recording from home, he found it liberating to be able to iterate freely without the pressure of making a good impression on every take: "I used to go into the studio to record. Now I'm doing it more from home, and I think I take a lot more risks at home because no one's gonna hear. They only hear what I send them (the final product) whereas if I'm in the studio, the song writer is in the room listening to every take I do, and I always wanna create a good impression. I wanna get hired again." (P36)

4.1.2 Technological Desires and Implications. To help create environmental variety, one participant cited the possibility of immersive virtual reality: "I would love it if I could use virtual reality to go to Walmart or go to Target...give me those inspirations that I need for my music." (P8) Another described the desire for an ambient screen that displays different environments: "I've actually seen like Skrillex [a professional musician] using a TV and it displays like different environments...he's just like working on music and being able to see that." (P28) In general, participants seem to still be wrestling with how to reliably inject variety into their daily practices to inspire creativity, suggesting opportunities for design.

Participants also appeared to be in the early stages of recreating psychologically safe spaces when working with others remotely. Prior work has examined the challenges and value of creating safe spaces for online communities (e.g., [49]). The rapid shift to remote collaboration may mean that the music-makers in our study have not yet had time to adapt social protocols and expectations from collocated music-making to an online setting. Explicitly adopting a set of "rules and expectations" for remote collaborations, along with exercises similar to those used by improv instructors (e.g. 
Music for People ${ }^{1}$ ), may help address the absence of rich, real-time communications typical of collocated music-making.

\subsection{Time}

The pandemic has disrupted the daily schedules of both hobbyist and professional musicians, often with negative effects to their routine creative practices. For some people, these changes have led to less time in their schedules, leading to hyper-fragmented time, while others now have more time in their schedules, leading to more amorphous, unstructured time.

For many hobbyists, the pandemic has either threatened their pre-existing means of income, or increased demands at their current jobs, leading many to feel too busy to create music: "I find myself doing a lot more freelance and scrambling around to make money and that cuts into what I thought would be free time to make music." (P29) A need to cope with changes and health precautions at work has also consumed the time and energy that would have otherwise been reserved for music-making: "Now they're wearing gloves and masks and you know you're trying to stay far away from people. Your eight hour day feels like a twelve hour day. And then to come home we've got a four year old son and I'm cooking dinner and I'm paying the bills...it's just I'm done." (P14) As a result, there is little time left at the end of the day to make music: "I'm ready for sleep when I'd usually pick up the guitar." (P9)

For some professionals, cancelled gigs, tours, and concerts have introduced more temporal freedom, but this lack of structure has also brought with it a sense of time being more amorphous, leading to a loss of creative purpose and some difficulty staying productive. For example, one professional musician contrasted this temporal fluidity against his previously deadline-driven work ethic: "I'm finding new ways to procrastinate. [Previously] someone's paying me to do the job [and] I have to do it in the time frame they've given me...Get it done and send it over. [Now] I have the whole day, it's easy to just do something else. I think a lot of people are learning how to adjust with working from home that way." (P36)

4.2.1 Addressing Temporal Disruptions to Creative Practices. A few hobbyists attempted to cope with limited time by explicitly scheduling and carving out time for music activities: "I have scheduled a set time three times a week to just write...I wrote a song last night." (P22) However, most were resigned to the reality of no longer having time for music. Professionals and work-from-home hobbyists with additional, unstructured time sought to find a more regular sense of purpose, such as participating in monthly album recording projects, or joining remote, virtual orchestras that would require them to play and perform: "Let's give ourselves something to practice, cause we're not gigging. Let's give ourselves a performance scenario to motivate us to play." (P35) These behaviors resonate with Mekler and Hornbæk's previously referenced theoretical framework for the experience of meaning, which posits that when meaning is disrupted or threatened by stressful or inexplicable events, people are motivated to reinstate a sense of meaning [40].

Some hobbyists and professionals are discovering some silver linings when presented with new blocks of time in their schedule.

\footnotetext{
${ }^{1}$ https://www.musicforpeople.org/wp/
}

Many have taken this uninterrupted time to re-engage with past creative projects, develop new professional skills, create more longerterm intentionality in their art, and reconnect with the humanistic, restorative power of music: "Constraints do foster creativity... a lot of us are reviving projects we haven't done in a while." (P30)

A temporary pause from gig culture has allowed some to reflect on a fragmented and reactive lifestyle: "Fump from one gig to the next, different city every night, you're in and out. There's a creative cost to that. Musicians don't have the time and space to create projects of their own initiative, and present them on their own terms, for their own function." (P35). This has prompted a re-consideration of how one might retain more long-term intentionality and control as an artist, if and when gigs and performances return: "How to...have more intentional projects, more creative control, more sustained time and place devoted to them?" (P35) In this quote and others in this section, we see evidence of the music-makers working to ensure a sense of significance and coherence to their activities and their time, thereby preserving and creating meaning [40].

4.2.2 Technological Desires and Implications. Among those who felt too busy to find time for music, very few had identified strategies for recuperating creative value from fragmented or busy schedules, despite a plethora of calendaring and productivity apps available online. Partly, this could be because "life hack" apps are not easily customizable for sensing non-standard activities or for producing arbitrary, user-defined actions: "If there was some type of alarm or app that would tell me, Hey it's been six hours...since you last touched your instrument why don't you play a little bit just relax." (P2) For example, while there are many apps for sensing physical exercise, or for triggering context-aware, domain-specific activities (e.g. vocabulary learning [27]), it is not easy to personalize or generalize them to other domains such as instrument practice.

There is also value in supporting long-term intentionality in creative pursuits, including re-visiting past artistic creations in creative ways, setting long-term professional and artistic goals, and attaining those long-term creative goals despite small chunks of potentially-interrupted time. In this spirit, there is an opportunity to revisit micro-creativity, and bringing lessons learned in crowdwork [51] for the purpose of helping people make incremental progress towards long-term creative aspirations [55]. For example, given that moderate time constraints can be fruitful mechanisms for spurring playfulness and creativity [5], there is an opportunity to capitalize on time dynamics for micro-creativity.

\subsection{Creative Mindsets and Stress}

The inability to physically meet and congregate with others has effectively removed the ability to hold collocated live concerts, practice sessions, and classes. Online versions of these same activities are severely degraded and in many cases, infeasible. This inability to meet in person and be with others threatens musicians' preexisting income streams, reduces their ability to effectively practice their craft, and affects how they socialize with one another in the community. Together, these disruptions have led to increased levels of stress, making it difficult to produce creative mindsets.

Disruptions to finances and the inability to meet face-to-face have contributed to lower energy levels and resulted in mindsets not conducive to creative pursuits: "The financial stress and all that 
is required of me to find some stability. I have to have stability and security to feel creative, to express myself creatively otherwise I'm too tired or distracted." (P22) As a result, some participants don't engage in the practice as frequently, and when they do, they might not feel as engaged as they did before: "I generally feel like I'm just going through the motions when I play. There's so much of an emotional lock right now that I can't get out my ideas. I've been trying to change it up and reverse my practice schedule, or try new pieces, or whatever I can think of." (P3) Another participant conveyed the mental load they carry: "Honestly, it's my brain that feels full. I attribute it to the stress we're all under, because it takes more intentionality to clear my brain and focus when I want to make music." (P7)

Beyond themselves, participants also mentioned how difficult it was to motivate others to engage in the practice: "The biggest challenge for me has been the fact that I am no longer allowed to meet with my students to run rehearsals. Our concerts have been cancelled and it is incredibly difficult to motivate my students who are typically motivated by singing together as a group and creating music together and sharing the experience of growth and progress with one another." (P1)

4.3.1 Addressing Stress and the Need for a Creative Mindset. Several participants actively turned to music to relieve stress, such as "recording and producing...meditation music" or "trying to relieve some stress by playing the piano." (P1) While unintentional, one participant discovered through playing music that it could serve as a form of therapy: "When I do get to play and find myself inspired enough to try a bunch of different things the music is providing more of an escape at that moment...to free my mind." (P29)

Interestingly, while some participants recognized that musicmaking itself could help alleviate stress, they were usually unable to identify a means for initiating music-making when stressed. From a behavioral lens, this may point to the lack of persuasive triggers or emotional ability for making music, despite having the intrinsic motivation to do so [21].

4.3.2 Technological Desires and Implications. Recognizing the utility of triggers and prompts to engage in creative practice, participants offered ideas on how technology could help fill this need: "Maybe if there was ... an app where people...all they need is to like hear somebody play a saxophone or you know talk to somebody and hear them play music or something like that. Maybe that would get me distracted enough to be able to do that." Others emphasized that these triggers would need to be lighthearted, persuasive, and not heavyweight, to coax engaging in creative practice: "Mocktail or something...just make it kind of a fun event." (P5)

\subsection{Social Connections and Interactions}

A key part of many participants' practice is playing and/or working with others. Many of these social interactions must now be mediated through synchronous and asynchronous communication tools, such as video conferencing, email, phones, and livecasting.

In using existing communication tools, many participants stated that the most significant challenge for them has been internet latency, which has made it nearly impossible to conduct any form of real-time social improvisation online: "It's so frustrating. We don't have an online platform where people can hear each other without latency delays." (P31) Participants tried to use common video chat online platforms, but cited an inability to synchronize between players as a key barrier to real-time collaborative music creation. Many emphasized that although latency is more tolerable in other domains, it is a show-stopper in music: "[video conferencing software]...they're not meant to be duplex. They're OK for things that involve turn-taking, and OK for things that don't require a rhythmic pulse." (P31), "Dance is a little bit less offensive if the timing's off ... but for musicians they really want to hear 20 people playing a note at once." (P30)

The network latency also makes it challenging to creatively respond to each other in real-time. For most, adjusting and reacting to one another in real-time is fundamental to the creative pursuit: 'Let's say the drummer is playing his part, and you're joining in as a pianist. What can you play that complements his groove?... What's a missing accent that you can fill in?" (P35) This give-and-take of responding to others in real-time makes them come alive: "So much is about what the bass and drummer have given me, how we respond to each other. So much is about responding." (P35) This normal, backand-forth dialogue that yields in-the-moment creativity is much more difficult to replicate asynchronously. Because players cannot react to each other in real-time, some only recognize new changes they would like to make after the entire piece is finished: "We get to the end, we all listen together, then person number 2 goes 'now that I hear the whole beautiful structure, I wanna revise my part."' (P35) These observations point to a degradation of the moment-tomoment interactional processes of a group, which are often critical to the successful fulfillment of group creativity [48].

The video conferencing software used by participants results in notable audio degradation, which further impairs the experience: "Even like when you're on like a [video conference call] you can't hear all the nuances of the music, and it sounds ... the tone is bad and it would just be so much better if you hear everything better with a better streaming platform." (P21) As a result, participants indicated that they have had to stop playing (and performing) real-time improv altogether: "I've never gone this long without improvising with someone else." (P32) "Social distancing kills any possibility of ensemble music making." (P31)

The inability to recreate the visceral feel of working together has also been challenging. Participants pointed to the in-person nature of their profession as to what makes music improvisation fundamentally human. For example, a professional musician stated: "We're like blood sweat and tears. We like to be in the same room together. It's a real organic form of music. What keeps my heart and my soul pumping is communicating with other musicians." (P32)

Some musicians rely on income from live performances. Restrictions in physically congregating mean that these musicians must now move their livelihoods online to maintain an income. For some, this move requires developing new skills and expertise (e.g., creating and delivering a digital product, or engaging with an audience remotely), which can present unexpected hurdles. For example, to connect with an audience, some have co-opted widely used livestreaming platforms, but are concerned that audience support may only be short-lived: "They're being generous to support us but not cause they're getting a great product. The audio's not great. As someone who's organizing these livestreams, I want the product that we're giving our audience to be good. Nurturing our community, 
our audience, is so important. I want people to support us [because] we are giving them something that's valuable." (P36)

The next two subsections describe how participants have addressed these issues of latency in social interactions and the creation and maintenance of social connections.

4.4.1 Addressing Latency Issues in Social Interactions. Faced with the inability to synchronously create music together in real-time, many musicians have reverted to asynchronous practices, such as passing each other recordings and playing improv over them. Participants often emailed tracks to one another, with collaborators layering tracks on top of one another asynchronously.: "People would record a track, give it to someone else, they would add something, they would send it to someone else. It becomes making music in a very different way than making it in real-time." (P34) However, this practice does not live up to the in-person, real-time experience: "It's not human enough for me. I like to be in a room with musicians playing." (P32)

To support asynchronous practices, the use of online shared drives was also noted: "We have a [shared drive] setup, we organized all these different folders, a folder for sketches (a first track). Anyone is free to pull out that sketch, record something along with it, and then upload it to a "collaborations" folder. When enough people have piled on, someone will pull it out and make the reverb match, mixing things. Most of us are using Garageband, Protools, Logic, Audacity [for individual editing]" (P30). However, not everyone is familiar with shared drives, making email preferred by some: "We have found that a huge barrier for [people] to join this project has been being able to use [the shared drive]. So we are literally doing trainings. There are still people who prefer for me to email them tracks." (P30)

Despite the immense frustration with internet latency, several professionals found value in using space and silence as creative devices in their music-making, as those pauses occasionally fostered new ideas: "It inserts an extra level of pause. That's kind of interesting." (P30) For instance, a music improvisation instructor described how laggy music created new opportunities to embrace the unexpected: "How can it be different from what we [individually] actually heard, but still sound like a beautiful coherent piece of music? Maybe it still sounds cool, what pitches people are playing." (P34)

For others, the introduction of latency led to experimenting with new methods of social coordination. For example, one group deliberately tried to have fixed-time offsets for each player, by playing "I've been working on the railroad" in a strictly rhythmic way: "Some friends of mine got together on [video conferencing software] and tried [to] solve the issue of latency. If we play bpm 120 and I just play 1 beat off from you then we'll be together." However, rarely did they find this satisfying: "The person who is anticipating by a beat will always feel like it's not lined up." (P36) Others took a different approach, deliberately relaxing rhythm by introducing long stretches of silence. For instance, one participant described the positive collaborative benefits of being forced to create silences: "With people leaving more space, the pieces they were coming up with started to become more interesting. They're playing in a much more thoughtful way. They're actually having to listen...learning to play together in a new way." (P34)

Witnessing these adaptations, we note that the medium of communication is directly influencing both the types of music being created, and the social coordination of music-making. As one professional astutely put it, "With latency, it's like the artistic product has to change to reflect the fact that you're in a different sonic space" (P34), an observation that musician David Byrne has also made regarding the influence of performance spaces on music [11].

4.4.2 Addressing Social Connections. Whereas music improvisation communities have traditionally formed through physically gathering and jamming together, new large-scale, distributed communities are now emerging through virtual orchestras and choirs $^{23}$, global forums, and projects for a greater cause. For example, an emergent phenomenon is to instruct people to play the same composition individually in their own homes, then have a central person creatively edit them together. Reflecting on this experience, one participant remarked that, even though she was merely "playing by myself to a metronome in my ear," she felt an increased sense of belonging in a vibrant, global community: "It was a community builder. We were rooting for each other...I'm reaching out to people beyond the walls of my house." (P32)

The pandemic has also spurred many professionals to offer pro bono performances, or serve on expert panels freely broadcast worldwide. Through events like these, some felt that the pandemic may also be bringing music back to its humanistic, communitybased roots by making music and well-known artists more accessible to all: "It's driving home this concept that music, and especially jazz, is a community-based music. Music has become so commercial that it's easy to forget that it's actually just human community, 'let's be together' type of music." (P32) One participant hoped that these new platforms could broaden artists' professional scope beyond performance, even after the pandemic: "To talk and teach and lecture, to lead societal dialogues about this stuff, not just perform." (P35) Such global platforms could spur and enrich societal dialogues around music, beyond the playing of music itself.

On a more personal level, social distancing has prompted some to create music as a gift to family members and friends, in an effort to connect with them: "Because I can no longer see my friends in person, I am more likely to compose or improvise a song for them as a way of bringing more of a human touch to my interactions with them. (P20) "My friend's birthday is next Tuesday, and she wrote us all asking if we could send her some songs to listen to all day in lieu of a party! She doesn't know this yet, but I'm also going to write a song for her :-)” (P20)

4.4.3 Technological Desires and Implications. As noted, participants demonstrated a desire to continue working with other musicians, whether to compose music together or to play live together. Faced with this need to work remotely, participants indicated a desire to directly extend their existing, single-user creative software to remote collaborations in a shared digital environment: "I want Garageband in a Googledocs kind of way. Being able to go in there, both of us logged into our audio project together and we're making changes together. That would feel like live in-person collaboration." (P35) Though this would not enable the synchronous playing/performing of music (which would require no latency), it would enable synchronous recording and editing, which many felt

\footnotetext{
${ }^{2}$ https://www.youtube.com/watch?v=nS1dOZ5HFZQ

${ }^{3}$ https://www.youtube.com/watch?v=QagzdvzzHBQ
} 
would be a substantial step forward in allowing them to creatively react to others while their music is still evolving: "There's nothing really that allows you to open up your interfaces and record it together remotely...if me and my drummer could both have our Logic Pro set up and running and be basically like in a [video conference] meeting but recording directly... that would be really truly incredible." Despite an abundance of collaborative editing platforms in other domains (e.g. writing), and prior research in this area [54], it is not yet a straightforward matter to remotely share arbitrary software interfaces (e.g. Garageband, Logic Pro) so that everyone can interact directly with them.

This inability to easily transform traditional desktop applications into forms that allow for synchronous remote collaboration led participants to the fallback option of using email and shared drives to share rich media files. These asynchronous practices introduced some costs to the creative process. Without the benefit of being able to experiment with musical ideas in a collocated, real-time setting, musicians encounter long iteration times and the need to put ideas in a "finished file" format (P35) when collaborating remotely and asynchronously. In contrast, in-person collaborations afford rapid, informal experimentation.

Asynchronous collaborations achieved by passing around files also led to more deliberate communications about the composition and editing process: "The minute we do something new, we email each other 'hey we added some oboe to your country road song. Might have done a little too much, you can take out a few choruses if you want."' (P30) As a result, many have developed roundabout strategies for sending music in a form where it could be editable by others: "I recorded a cello part, violin part, viola part. Then I sent her each track individually so...if she just wants to hear one thing she can do that. If she wants to cut it off." (P36)

Finally, participants desired more reliable ways to bring their livelihoods online and widely broadcast their work, which is particularly important for professionals, who rely on an audience to make a living. For example, some desired support in learning "how to set up mics, how to setup software, set up audio interfaces that allow the keyboard to be recorded properly... That is a skill set quite independent of playing the instrument. That's really a learning curve for a lot of us." (P35) In particular, there is a desire to improve and sustain their audience's user experience, such as going beyond broadcasting to more live audience interactions, much like one might do at an in-person show.

\section{DISCUSSION}

The pandemic has created a unique global event that has, in many ways, uncovered the relative lack of flexibility in the digital tools and services that communities have come to rely on. Hobbyists and professionals alike faced major challenges, such as an inability to play together synchronously in real-time, a lack of psychological safe spaces, and a struggle to self-motivate and get into a creative mindset. Some professionals also needed to bring their livelihoods and audiences online in order to maintain an income. These disruptions help reveal how current digital tools have been optimized for very specific contexts and use cases. By examining where breakdowns have occurred in adapting to the remote interactions necessitated by the pandemic, we can more readily observe the underlying design assumptions of existing digital tools and services, which may otherwise be difficult to discern.

At the same time, the pandemic has also indirectly spurred a new wave of creativity witnessed in the variety of ways individuals responded to the crisis (e.g. creating new musical styles that better pair with latency or that explicitly incorporate silence; using spatial constraints as a source of creativity; creating music for selftherapy). For professionals, these breakthroughs also manifested in the form of major shifts in what it means to be a musician itself: The pandemic prompted professionals to engage in both large-scale, distributed collaborations and personal reflection on their own careers, leading some to desire longer-term intentionality in their profession. These creative breakthroughs and responses enable reflection on the challenges of creatively coping with crisis [59], and how HCI can better support these endeavors. In this section, we reflect on potential lessons that can be learned, both in creating more resilient technology (5.1-5.3), and in fostering and supporting creative mindsets during periods of disruption (5.4-5.5).

\subsection{End User-Extensible Tools for Remote Collaboration}

The pandemic forced the traditionally collocated activities of musicmakers (e.g., jamming, lessons, concerts) into a computer-mediated remote context. Despite the availability of remote communication software (e.g. Zoom, Hangouts) and a range of collaborative music apps (e.g. Ohmstudio, Jamkazam), it is noteworthy that musicians experienced fundamental challenges in their inability to easily play music together remotely. We observed multiple possible sources for the issues encountered: existing software can be highly optimized for use cases incompatible with musicians' needs (e.g., videoconferencing systems can introduce latency that is problematic for musicians); existing digital tools (e.g. digital audio workstations) are challenging to adapt to synchronous, real-time remote collaborations; platforms and software better suited to remote musical collaborations (e.g. online jamming platforms) require technical expertise to setup or involved overhead to learn; and relevant software or systems were sometimes simply not known to musicians.

Faced with the desire to continue music-making practices, and the inability to use their computational tools as desired, participants fell back on the tedious practices of emailing or sharing files that only one person can work on at a time, a slow and heavyweight mode of interaction. These experiences lay bare the underlying usecase assumptions embedded in the design of the tools and services participants use (e.g., a single user, desktop experience, with little or no ability for synchronous, remote collaboration). The experiences of participants also provide some indication of the relative inflexibility of the digital infrastructure they rely on. For example, they could not easily transform their computational devices and software into forms that allow synchronous remote collaboration. When solutions for problems did exist, participants indicated that they involved too much overhead, or required expertise to setup.

When presented with disruptions and changes to routine practices, the ability for end-users to customize or extend software in novel ways becomes a clear asset. In light of the challenges described above, there appears to be value in the ability to a) adapt 
existing desktop creative tools to remote, multi-user contexts (i.e., take an existing piece of software and enable its use remotely and in collaborative contexts, as in [54]), and b) adapt existing remote collaboration tools to desired creative practices (i.e., take existing remote collaboration technology, and allow users to extend it to new domain-specific use cases).

There is a rich history of work dedicated to end-user programming (e.g. [33]), toolkits to create groupware (e.g., [47]), and systems to transform single-user desktop applications into multi-user applications (e.g., [54]). The need for entire communities to swiftly respond to the pandemic and adapt software to their specific needs suggests that these lines of research are as relevant as ever, especially in times of disruption: the ability to swiftly adapt facilitates the creation of new digital infrastructure [50,52], while catalyzing innovation [23] (as discussed above in Related Work). More generally, tool adaptability can also provide flexibility that is useful during "normal," day-to-day practices. For example, as has been observed in prior work, if musicians can customize their digital tools so they interact with them in a hands-free manner, it allows them to keep their hands on their instruments [4].

\subsection{Semi-Synchronous Interactions}

Music-makers in our study attempted both synchronous practices (e.g. real-time improvisation over video chat) and asynchronous practices (e.g. emailing each other music files). In considering this spectrum of practices, there appears to be the potential to more thoroughly explore a semi-synchronous middle ground that provides some semblance of real-time creative interaction without requiring zero-lag solutions. For example, aside from wanting to play music together in real-time, participants had indicated a strong desire to edit music together in real-time, which would at least allow them to creatively respond to each other quickly, without long delays characteristic of emailing a composition to each band member in turn. Although this capability is currently pervasive in other domains (e.g. collaborative text editors), our participants did not cite any software used to edit music together in a shared composition doc. One interesting version of this paradigm is seen in Endlesss ${ }^{4}$, a collaborative, remote, looper-based music app that synchronizes a musical loop with all remote collaborators at once. Users can edit a local copy of the loop in real-time, and when satisfied, push their changes to all other collaborators, who can then immediately hear the updates. This type of semi-synchronous interaction paradigm provides effective ways of dealing with internet latency, while tightening the feedback and interaction loop between musicians.

\subsection{Awareness, Spontaneity, and Fluid Transitions Between Modes of Creative Collaboration}

Currently, remote collaboration when creating music is a somewhat heavyweight process, requiring some degree of deliberate planning and coordination (e.g. round-robin composition, large-scale virtual orchestras with post-hoc editing). It appears that, while current remote communication tools enable remote connectivity, these are

\footnotetext{
${ }^{4}$ https://endlesss.fm/
}

not ready substitutes for remote awareness or spontaneity. Conversely, in the collocated, physical realm, one can happen upon others, maintain awareness of their activities, and smoothly transition between activities and communication formalities (e.g., from casually hanging out to formally writing a song together, or from performing in a gig with a stranger to informal brainstorming afterward). Despite incredible advances in remote communication and collaboration tools, opportunities remain for systems that support a wider range of awareness and communication formalities. To this end, the extensive research in the realms of context-aware computing $[14,36]$ and peripheral interfaces [37] seems highly applicable to situations like the pandemic, which require remote collaboration. For example, there may be opportunities to automatically detect moments when people may be interruptible [29] to help individuals identify times when collaborators may be available for unplanned interactions. In general, mechanisms that help individuals maintain awareness and involvement with others in their community are likely to help preserve a sense of connection and purpose in the absence of the ability to physically collocate [40].

\subsection{Finding Creative Mindsets During Stress}

While some participants were able to find logistical workarounds for maintaining their creative practices, one of the more challenging aspects to cope with was the difficulty of conjuring creative mindsets while stressed. As seen in prior work, it can be challenging to initiate healthy, creative mindsets when stress levels are high [6], despite the potential benefits of creativity in mediating stress [38].

For those facing hyper-fragmented time, some wished they could receive persuasive prompts at just the right moments to engage themselves in music-making again. Given this, research on persuasive computing [22] and micro-tasks [13, 55] seem particularly germane, especially work that focuses on encouraging micro-creativity and healthy mindsets during times of stress. For example, a low effort activity of listening to music may eventually ease people into the mindset of playing or even improvising novel music. In helping people recuperate long-term creative value from what would otherwise be fragmented moments of time [56], these sorts of infrastructure could further help support long-term artistic intentionality and a sense of coherence [40] in one's creative purpose.

\subsection{Tools for Creative Resilience}

While some participants struggled to be creative during these stressful times, our study found that times of duress can also trigger creativity: Some participants creatively used the unique constraints of the pandemic as implicit creative prompts to spur new creative experiences and solutions (e.g., collecting in-home sounds, using latency as a creative device, distributed virtual orchestras). However, despite these rare proactive efforts, we did not observe participants turning to a common, "go-to" reference for creatively adapting to the crisis. In other words, there was no clear, common set of strategies, services, or tools that the majority of participants relied upon to help navigate the crisis of the pandemic.

Together, these observations suggest that, beyond building technology to directly support remote creativity, there is value in codifying and formalizing effective strategies for responding to life disruptions. While this paper uncovers many examples of creative 
adaptations, it also adds to a growing body of research on creativity during crisis management $[45,59]$. Flexible, creative mindsets during disruptive times will always be useful, suggesting the value in continuing to synthesize implications for the design of tools that help people not only restore normality, but also create genuinely novel solutions during mass disruption.

\section{CONCLUSION}

This paper conveys the experiences of music-makers adapting their lives, livelihoods, and creative practices in response to the disruptions brought on by the global pandemic. The results offer a snapshot of a creative community in transition to a "new normal." By observing their use of space, time, and social connections in their creative practices, we see ways in which existing technological infrastructure was robust to changes, and ways in which it could be more flexible and resilient. These observations contribute to a broader discussion of how to design technology, particularly remote collaboration tools, to be more robust in the face of large-scale, rapid-onset disruptions to daily routine.

\section{ACKNOWLEDGMENTS}

The authors would like to thank Ian Simon, Jesse Engel, Doug Eck, Martin Wattenberg, and Dan Russell for their support and feedback on this research.

\section{REFERENCES}

[1] Neil Anderson, Carsten KW De Dreu, and Bernard A Nijstad. 2004. The routinization of innovation research: A constructively critical review of the state-ofthe-science. Fournal of organizational Behavior 25, 2 (2004), 147-173.

[2] Frank M Andrews and George F Farris. 1972. Time pressure and performance of scientists and engineers: A five-year panel study. Organizational Behavior and Human Performance 8, 2 (1972), 185-200.

[3] Cecilia R Aragon and Alison Williams. 2011. Collaborative creativity: a complex systems model with distributed affect. In Proceedings of the SIGCHI Conference on Human Factors in Computing Systems. 1875-1884.

[4] Juan Pablo Martinez Avila, Chris Greenhalgh, Adrian Hazzard, Steve Benford, and Alan Chamberlain. 2019. Encumbered Interaction: A Study of Musicians Preparing to Perform. In Proceedings of the 2019 CHI Conference on Human Factors in Computing Systems (Glasgow, Scotland Uk) (CHI '19). Association for Computing Machinery, New York, NY, USA, 1-13. https://doi.org/10.1145/3290605.3300706

[5] Markus Baer and Greg R Oldham. 2006. The curvilinear relation between experienced creative time pressure and creativity: moderating effects of openness to experience and support for creativity. Journal of Applied Psychology 91, 4 (2006) 963.

[6] Robert S Baron. 1986. Distraction-conflict theory: Progress and problems. In Advances in experimental social psychology. Vol. 19. Elsevier, 1-40.

[7] Virginia Braun and Victoria Clarke. 2019. Reflecting on reflexive thematic analysis. Qualitative Research in Sport, Exercise and Health 11, 4 (2019), 589-597. https://doi.org/10.1080/2159676X.2019.1628806 arXiv:https://doi.org/10.1080/2159676X.2019.1628806

[8] Nick Bryan-Kinns. 2004. Daisyphone: the design and impact of a novel environment for remote group music improvisation. In Proceedings of the 5th conference on Designing interactive systems: processes, practices, methods, and techniques. 135-144.

[9] David Bunce and Michael West. 1994. Changing work environments: Innovative coping responses to occupational stress. Work \& Stress 8, 4 (1994), 319-331.

[10] Philip L Burk. 2000. Jammin'on the Web-a new Client/Server Architecture for Multi-User Musical Performance.. In ICMC. Citeseer.

[11] D. Byrne. 2017. How Music Works. Crown. https://books.google.com/books?id= Aa7NDAAAQBAJ

[12] Kristin Byron, Shalini Khazanchi, and Deborah Nazarian. 2010. The relationship between stressors and creativity: a meta-analysis examining competing theoretical models. Fournal of Applied Psychology 95, 1 (2010), 201.

[13] Carrie J Cai, Philip J Guo, James R Glass, and Robert C Miller. 2015. Wait-learning: Leveraging wait time for second language education. In Proceedings of the 33rd Annual ACM Conference on Human Factors in Computing Systems. 3701-3710.

[14] Carrie J Cai, Anji Ren, and Robert C Miller. 2017. WaitSuite: Productive use of diverse waiting moments. ACM Transactions on Computer-Human Interaction
(TOCHI) 24, 1 (2017), 1-41.

[15] Chris Chafe, Scott Wilson, Randal Leistikow, Dave Chisholm, and Gary Scavone. 2000. A simplified approach to high quality music and sound over IP. In Proceedings of the COST G-6 Conference on Digital Audio Effects (DAFX-00). Citeseer, 159-164.

[16] Kathy Charmaz. 2006. Constructing grounded theory: A practical guide through qualitative analysis. sage.

[17] Palle Dahlstedt, Per Anders Nilsson, and Gino Robair. 2014. The Bucket System. (2014).

[18] Jill P. Dimond, Erika Shehan Poole, and Sarita Yardi. 2010. The Effects of Life Disruptions on Home Technology Routines. In Proceedings of the 16th ACM International Conference on Supporting Group Work (Sanibel Island, Florida, USA) (GROUP '10). Association for Computing Machinery, New York, NY, USA, 85-88. https://doi.org/10.1145/1880071.1880085

[19] Umer Farooq, John M Carroll, and Craig H Ganoe. 2005. Supporting creativity in distributed scientific communities. In Proceedings of the 2005 international ACM SIGGROUP conference on Supporting group work. 217-226.

[20] Umer Farooq, John M Carroll, and Craig H Ganoe. 2007. Supporting creativity with awareness in distributed collaboration. In Proceedings of the 2007 international ACM conference on Supporting group work. 31-40.

[21] BJ Fogg. 2009. A Behavior Model for Persuasive Design. In Proceedings of the 4th International Conference on Persuasive Technology (Claremont, California, USA) (Persuasive '09). Association for Computing Machinery, New York, NY, USA, Article 40, 7 pages. https://doi.org/10.1145/1541948.1541999

[22] Brian J Fogg. 2002. Persuasive technology: using computers to change what we think and do. Ubiquity 2002, December (2002), 2.

[23] Stephen Graham and Nigel Thrift. 2007. Out of Order: Understanding Repair and Maintenance. Theory, Culture \& Society 24, 3 (2007), 1-25. https://doi.org/ 10.1177/0263276407075954 arXiv:https://doi.org/10.1177/0263276407075954

[24] Michael Gurevich. 2006. JamSpace: designing a collaborative networked music space for novices. In Proceedings of the 2006 conference on New interfaces for musical expression. 118-123.

[25] Suzanne B Hanser. 1985. Music therapy and stress reduction research. Fournal of Music therapy 22, 4 (1985), 193-206.

[26] Steve Harrison and Paul Dourish. 1996. Re-Place-Ing Space: The Roles of Place and Space in Collaborative Systems. In Proceedings of the 1996 ACM Conference on Computer Supported Cooperative Work (Boston, Massachusetts, USA) (CSCW '96). Association for Computing Machinery, New York, NY, USA, 67-76. https: //doi.org/10.1145/240080.240193

[27] Ari Hautasaari, Takeo Hamada, Kuntaro Ishiyama, and Shogo Fukushima. 2019. VocaBura: A Method for Supporting Second Language Vocabulary Learning While Walking. Proceedings of the ACM on Interactive, Mobile, Wearable and Ubiquitous Technologies 3, 4 (2019), 1-23.

[28] James Hollan, Edwin Hutchins, and David Kirsh. 2000. Distributed Cognition: Toward a New Foundation for Human-Computer Interaction Research. ACM Trans. Comput.-Hum. Interact. 7, 2 (June 2000), 174-196. https://doi.org/10.1145/ 353485.353487

[29] Scott Hudson, James Fogarty, Christopher Atkeson, Daniel Avrahami, Jodi Forlizzi, Sara Kiesler, Johnny Lee, and Jie Yang. 2003. Predicting Human Interruptibility with Sensors: A Wizard of Oz Feasibility Study. In Proceedings of the SIGCHI Conference on Human Factors in Computing Systems (Ft. Lauderdale, Florida, USA) (CHI '03). Association for Computing Machinery, New York, NY, USA, 257-264. https://doi.org/10.1145/642611.642657

[30] Edwin Hutchins. 1991. The social organization of distributed cognition. (1991).

[31] Ioanna Iacovides and Elisa D. Mekler. 2019. The Role of Gaming During Difficult Life Experiences. In Proceedings of the 2019 CHI Conference on Human Factors in Computing Systems (Glasgow, Scotland Uk) (CHI '19). Association for Computing Machinery, New York, NY, USA, 1-12. https://doi.org/10.1145/3290605.3300453

[32] Sergi Jordà. 2002. FMOL: Toward user-friendly, sophisticated new musical instruments. Computer Music fournal 26, 3 (2002), 23-39.

[33] Andrew J Ko, Brad A Myers, and Htet Htet Aung. 2004. Six learning barriers in end-user programming systems. In 2004 IEEE Symposium on Visual LanguagesHuman Centric Computing. IEEE, 199-206.

[34] Elise Labbé, Nicholas Schmidt, Jonathan Babin, and Martha Pharr. 2007. Coping with stress: the effectiveness of different types of music. Applied psychophysiology and biofeedback 32, 3-4 (2007), 163-168.

[35] J Leach. 2001. MetaTone: Shared Environment for musical collaboration. MSc IT Thesis, Queen Mary, University of London (2001).

[36] Brian Y Lim and Anind K Dey. 2011. Design of an intelligible mobile contextaware application. In Proceedings of the 13th international conference on human computer interaction with mobile devices and services. 157-166.

[37] Blair MacIntyre, Elizabeth D Mynatt, Stephen Voida, Klaus M Hansen, Joe Tullio, and Gregory M Corso. 2001. Support for multitasking and background awareness using interactive peripheral displays. In Proceedings of the 14th annual ACM symposium on User interface software and technology. 41-50.

[38] Lily Martin, Renate Oepen, Katharina Bauer, Alina Nottensteiner, Katja Mergheim, Harald Gruber, and Sabine C Koch. 2018. Creative arts interventions for stress 
management and prevention-a systematic review. Behavioral Sciences 8, 2 (2018),

[39] Michael Massimi, Jill P. Dimond, and Christopher A. Le Dantec. 2012. Finding a New Normal: The Role of Technology in Life Disruptions. In Proceedings of the ACM 2012 Conference on Computer Supported Cooperative Work (Seattle, Washington, USA) (CSCW '12). Association for Computing Machinery, New York, NY, USA, 719-728. https://doi.org/10.1145/2145204.2145314

[40] Elisa D. Mekler and Kasper Hornbæk. 2019. A Framework for the Experience of Meaning in Human-Computer Interaction. In Proceedings of the $2019 \mathrm{CHI}$ Conference on Human Factors in Computing Systems (Glasgow, Scotland Uk) (CHI '19). Association for Computing Machinery, New York, NY, USA, 1-15. https://doi.org/10.1145/3290605.3300455

[41] Tim Merritt, Weiman Kow, Christopher Ng, Kevin McGee, and Lonce Wyse. 2010 Who makes what sound? Supporting real-time musical improvisations of electroacoustic ensembles. In Proceedings of the 22nd conference of the computer-human interaction special interest group of Australia on computer-human interaction. 112-119.

[42] Roger Haigh Mills. 2011. Tele-Improvisation: Cross-Cultural Creativity in Networked Improvisation. In Proceedings of the 8th ACM Conference on Creativity and Cognition (Atlanta, Georgia, USA) (C\&C'11). Association for Computing Machinery, New York, NY, USA, 465-466. https://doi.org/10.1145/2069618.2069753

[43] Jennifer James Nicol and Bonita C Long. 1996. Creativity and perceived stress of female music therapists and hobbyists. Creativity Research fournal 9, 1 (1996), $1-10$.

[44] Gary M Olson and Judith S Olson. 2000. Distance matters. Human-computer interaction 15, 2-3 (2000), 139-178.

[45] Christine M Pearson and S Amy Sommer. 2011. Infusing creativity into crisis management: An essential approach today. Organizational Dynamics 40, 1 (2011), $27-33$.

[46] Amon Rapp, Maurizio Tirassa, and Lia Tirabeni. 2019. Rethinking Technologies for Behavior Change: A View from the Inside of Human Change. ACM Trans Comput.-Hum. Interact. 26, 4, Article 22 (June 2019), 30 pages. https://doi.org/10. $1145 / 3318142$

[47] Mark Roseman and Saul Greenberg. 1996. Building Real-Time Groupware with GroupKit, a Groupware Toolkit. ACM Trans. Comput.-Hum. Interact. 3, 1 (March 1996), 66-106. https://doi.org/10.1145/226159.226162

[48] R Keith Sawyer and Stacy DeZutter. 2009. Distributed creativity: How collective creations emerge from collaboration. Psychology of aesthetics, creativity, and the arts 3, 2 (2009), 81.
[49] Morgan Klaus Scheuerman, Stacy M. Branham, and Foad Hamidi. 2018. Safe Spaces and Safe Places: Unpacking Technology-Mediated Experiences of Safety and Harm with Transgender People. Proc. ACM Hum.-Comput. Interact. 2, CSCW, Article 155 (Nov. 2018), 27 pages. https://doi.org/10.1145/3274424

[50] Bryan Semaan. 2019. 'Routine Infrastructuring' as 'Building Everyday Resilience with Technology': When Disruption Becomes Ordinary. Proc. ACM Hum.-Comput. Interact. 3, CSCW, Article 73 (Nov. 2019), 24 pages. https://doi.org/10.1145/ 3359175

[51] Pao Siangliulue. 2015. Intelligent Systems to Support Large-Scale Collective Creative Idea Generation. In Proceedings of the 2015 ACM SIGCHI Conference on Creativity and Cognition. 327-328.

[52] Susan Leight Star. 1999. The Ethnography of Infrastructure. American Behavioral Scientist 43, 3 (1999), 377-391. https://doi.org/10.1177/00027649921955326 arXiv:https://doi.org/10.1177/00027649921955326

[53] Miyuki Suda, Kanehisa Morimoto, Akiko Obata, Hideaki Koizumi, and Atsushi Maki. 2008. Emotional responses to music: towards scientific perspectives on music therapy. Neuroreport 19, 1 (2008), 75-78.

[54] Chengzheng Sun, Steven Xia, David Sun, David Chen, Haifeng Shen, and Wentong Cai. 2006. Transparent Adaptation of Single-User Applications for Multi-User Real-Time Collaboration. ACM Trans. Comput.-Hum. Interact. 13, 4 (Dec. 2006), 531-582. https://doi.org/10.1145/1188816.1188821

[55] Jaime Teevan, Shamsi T Iqbal, Carrie J Cai, Jeffrey P Bigham, Michael S Bernstein, and Elizabeth M Gerber. 2016. Productivity decomposed: Getting big things done with little microtasks. In Proceedings of the 2016 CHI Conference Extended Abstracts on Human Factors in Computing Systems. 3500-3507.

[56] Jaime Teevan, Daniel J Liebling, and Walter S Lasecki. 2014. Selfsourcing personal tasks. In CHI'14 Extended Abstracts on Human Factors in Computing Systems. 2527-2532.

[57] Warren H Teichner, Edward Arees, and Raymond Reilly. 1963. Noise and human performance, a psychophysiological approach. Ergonomics 6, 1 (1963), 83-97.

[58] Kumiko Toyoshima, Hajime Fukui, and Kiyoto Kuda. 2011. Piano playing reduces stress more than other creative art activities. International fournal of Music Education 29, 3 (2011), 257-263.

[59] Gary R Webb and Francois-Regis Chevreau. 2006. Planning to improvise: the importance of creativity and flexibility in crisis response. International fournal of Emergency Management 3, 1 (2006), 66-72.

[60] Nechama Yehuda. 2011. Music and stress. Fournal of Adult Development 18, 2 (2011), 85-94. 